\title{
A Game Theoretic Model of Deposit Contracts between the Bank and the Depositor - Extend Study on the Economic Analysis of Bank Run
}

\author{
Jue-Shyan Wang ${ }^{1} \&$ Chiao-Hsin Lin $^{1}$ \\ ${ }^{1}$ Department of Public Finance, National Chengchi University, Taiwan \\ Correspondence: Jue-Shyan Wang, Professor, Department of Public Finance, National Chengchi University, 64, \\ Tz-nan Road, Sec. 2, Wenshan, Taipei, 116, Taiwan. E-mail: jswang@nccu.edu.tw
}

Received: May 23, 2014

Accepted: June 5, 2014

Online Published: June 18, 2014

doi:10.5430/ijfr.v5n3p136

URL: http://dx.doi.org/10.5430/ijfr.v5n3p136

\begin{abstract}
This paper which extends the settings of Chen and Hasan (2008) uses the game theoretic model to focus on the topics of not only interactive policies between a bank and a depositor but bank runs. Our study discovers that depending on different economic terms, the bank will probably propose two different deposit contracts for depositor to accept or not. After the acceptance of the deposit contract, the depositor will choose his withdrawal time on the basis of different liquidity preferences. On the other hand, bank runs occur only when one of the deposit contracts is proposed and the negative information of the investment project is disclosed to depositors.
\end{abstract}

Keywords: deposit contract, bank run, lender; signal, subgame perfect equilibrium

\section{Introduction}

Since the outbreak of the 1997 Asian financial crisis, Hong Kong's Bank of East Asia (abbreviated to BEA) firstly suffered a bank run on September 22, 2008. The event resulted from that people spread malicious rumors about BEA's stability via Short Message Service (SMS). They told the stories that BEA was encountering financial difficulties because of the capital losses from investment in Lehman bonds and American International Group (AIG). BEA was said to be taken over by the government of Hong Kong. Then Deputy Chief Executive of BEA issued a statement to clarify that the financial position of BEA was healthy and indicated that the rumor mongers were an attempt to undermine the stability of the financial system. However, queues of depositors sought to withdraw money from banks. To solve the problem of bank run, the Chief Executive Officer of BEA clarified again and the monetary authority of Hong Kong and the Financial Secretary were publicly behind BEA and guaranteed the safety and soundness of the banking system. This event thus ultimately subsided on September 25, 2008.

Some literature studies about the issue of bank runs. Diamond and Dybvig (1983) point out that under the deposit insurance system, bank will provide a superior deposit contract. And such a deposit contract will be likely to prevent the occurrence of bank runs. Chari and Jaganathan (1988) find that a bank run is induced by adverse information of the bank and the properties of information about the underlying investment returns will influence the choice between deposit contracts or equity contracts in the absence of deposit insurance system. Cooper and Ross (1998) indicate that the banks cope with its deposit contract design and investment decisions according to the probability of bank run. Besides, banks may provide a deposit contract to prevent bank runs. But under certain conditions, banks will choose a deposit with the risk of bank runs in order to get a higher expected return from the investments. Chen (1999) finds that on the condition of sequential service constrains and information asymmetry, the negative information from few banks may lead to large-scale panic run even to the collapse of the entire financial system. Samartín (2003) points out that bank runs are likely to be induced by message or panic. The deposit contract can be properly designed to avoid bank runs. But in some cases, the bank run may generate more benefits. Goldstein and Pauzner (2005) modify the model of Diamond and Dybvig (1983) and find that when the bank improves overall welfare and designs a deposit contract, there will be a trade-off between the trading liquidity benefits and the costs of a bank run which are both brought from the deposit contract. Alonso (1996) analyzes the banking environment and finds that negative information about the investment performance of the bank may lead to bank runs. Banks can prevent the occurrence of bank runs by designing appropriate deposit contracts. In some cases, avoiding bank runs can maximize the profits of the banks. However, the occasional runs can be the optimum bank behavior in other cases. Chen and Hasan (2006) indicate that increasing the information transparency of banks will make higher incidence of infectious runs, thereby 
reducing depositors' welfare. They also point out that it can reduce the incidence of runs if the deposit insurance system is designed as that some depositors are fully insured and the others are partially insured. Ennis and Keister (2006) point out that the bank will provide a deposit contract with risk of runs when the incidence of runs is very small. In the case of not preventing bank runs, the bank will choose to hold an amount of reserves just equal to the demand of withdrawal. When the cost of early liquidating investment is high, a rise in the incidence of runs may lead the bank to reduce the investment. Chen and Hasan (2008) use the symmetric pure-strategy subgame-perfect equilibrium to explain why the bank run is caused by depositors' panic. They note that in large-scale bank runs, the depositors were often unable to distinguish between good banks and bad banks, so they swarm into banks to withdraw. Maeda and Sakai (2008) propose that basing on the lender of last resort theory (LLR), the original deposit contract resulting in bank runs may make allocation of funds more efficient because the central bank can provide liquidity supply for banks with insufficient liquidity.

The model established by Chen and Hasan (2008) assumes that the bank makes zero economic profit and is in a passive position. Depositors make strategic decisions against changes in the economic environment, while the bank does not fight for its own interest. This is more like a model in which the depositor makes decision by himself. We modify the setting of Chen and Hasan into a competitive game model in which there is an interaction between the bank and the depositor. There are two types of depositors who will make decisions for profit maximization separately. We establish an extensive form game to solve for the equilibrium. The conclusion is that according to different economic terms, there will be two different deposit contracts proposed by the bank. And the depositor will choose withdrawal time in light of his liquidity preference. Moreover, we find that only one of these two contracts will bring about bank runs when the depositors receive the negative information of the investment project. This paper can provide the other angle for viewing the issue of bank runs.

The structure of the paper is organized as follows: Section 1 is the introduction. Section 2 describes the settings of our model. Section 3 solves for the equilibrium. Section 4 discusses bank runs. Concluding remarks are in Section 5.

\section{The Model}

The settings of this paper are mainly base on and thereby modified from the theoretical model of Chen and Hasan (2008). (Note 1) Suppose there are three decision-making dates (date 0, 1, and 2), besides a bank and a risk-neutral depositor existing in the society. At period 0 , the depositor possesses a unit of endowment, then choosing whether he saves the endowment at the bank or not. In the meanwhile, the bank provides a deposit contract $d_{2}$ (i.e., the bank will gives the depositor $d_{2}$ when the contract matures at period 2, yet the depositor will get $d_{1}$, if he withdrawals at period 1 in advance, and we continue the settings of Chen and Hasan (2008), $d_{2}>d_{1}>1$ ) to attract the depositor. If the depositor rejects the deposit contract, he still retains the original endowment, while the bank gets no return, and finally the game ends; if the depositor accepts the deposit contract, then the Bank may use the funds to carry out an investment plan. This investment plan expires at period 2 , one of its expected returns is $R$ with probability $p$, yet the other is 0 with probability $(1-p)$. Suppose the plan's expected rate of return $p R>1$, and if the bank liquidates the investment at period 1 , liquidation value of this investment plan is 0 .

In order to discuss the liquidity needs the depositor may face, assume that before the end of period 1, the depositor will divide into two types. It means that he will become type 1 with probability $t$, who must consume at period 1 to get utility, or will get no consumer utility at period 2, while the remaining probability $(1-t)$ is type 2 , who has no need for liquidity at period 1 . Assume that depositor does not know his type at period 0 , and the depositor of type 2 will receive a public signal $s$ concerning $p$ at period 1 . The public signal $s$ is of positive information $H$ with probability $\theta$, and is of negative information $L$ with probability $(1-\theta)$, where $\theta \in(0,1)$. The probability is $p_{H} \equiv p q /[p q+(1-p)(1-q)]$ when the expected return is $R$ caused by $s=H$, while $p_{L} \equiv p(1-q) /[p(1-q)+(1-p) q]$ is the probability when a return is $R$ caused by $s=L$, where $q \in(1 / 2,1)$ is the precision of the signal $s$ resulting in $p_{L} \leq p \leq p_{H}$. (Note 2) In Figure 1 we display the above-described problems are in an extension-type game tree, which the action of the depositor withdrawing in period 1 is $a_{1}$, while in period 2 is $a_{2}$. On the other hand, we do not introduce an insurance system in the discussion, that is, once banks fails in the investment plan, the depositor will receive no reward. According to the 
above description, if the depositor withdraws at period 1 , the depositor gets $d_{1}$, while the bank pays $-d_{1}$; if the depositor withdraws at period 2, the bank will get $p\left(R-d_{2}\right)$, the depositor of type 1 will get no utility because of not satisfied his liquidity needs, and the depositor of type 1 will get $p_{H} d_{2}$ and $p_{L} d_{2}$ respectively based on the quality of the signal.

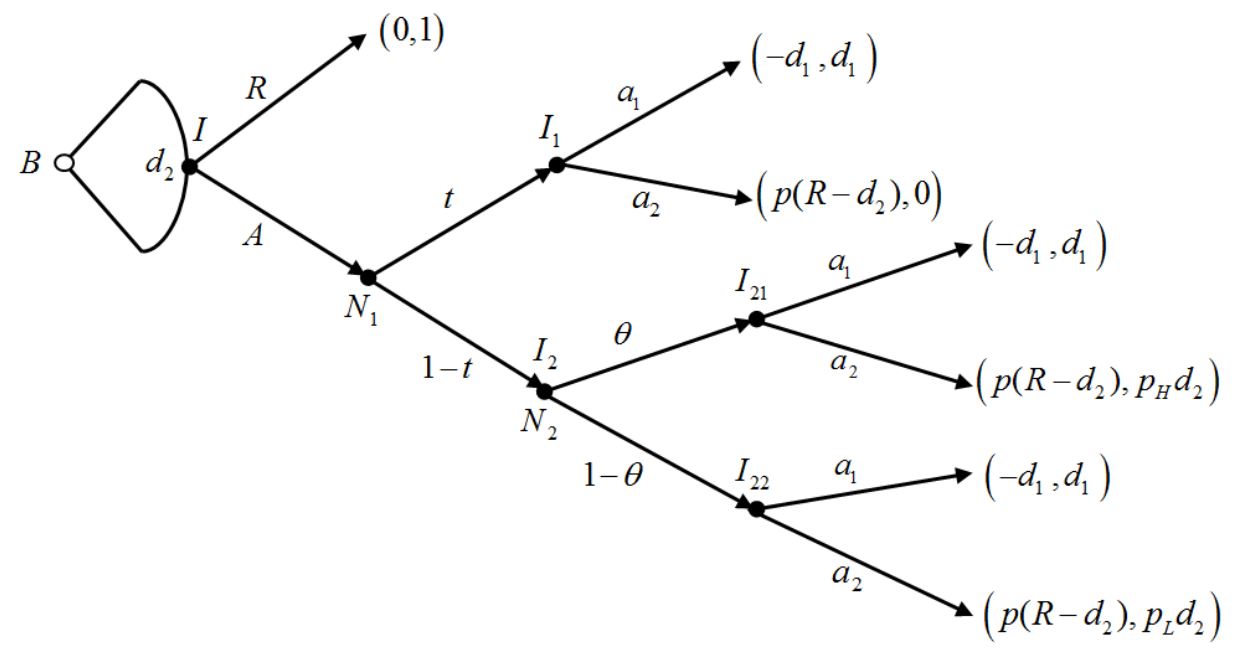

Figure 1. The extension-type game tree of the model

In this paper, we use backward induction to solve for the subgame perfect equilibrium.

\section{The Equilibrium}

At the decision point $I_{21}$, after the depositor of type 2 receives the signal of positive information $H$, the expected utility of his withdrawal in period 2 (i.e., taking action $a_{2}$ ) is:

$$
p_{H} d_{2} \equiv \frac{p q}{p q+(1-p)(1-q)} d_{2}
$$

Compare equation (1) with the utility $d_{1}$ of the depositor of type 2 withdrawing in period 1 (i.e., taking action $a_{1}$ ), we suppose $p q d_{2} /[p q+(1-p)(1-q)]$ is not less than $d_{1}$, meaning he will withdraw in period 2 after receiving the signal of positive information $H$. (Note 3 )

At the decision point $I_{22}$, after the depositor of type 2 receives the signal of negative information $L$, the utility of taking action $a_{2}$ is:

$$
p_{L} d_{2} \equiv \frac{p(1-q)}{p(1-q)+(1-p) q} d_{2}
$$

Compare equation (2) with the utility $d_{1}$ of the depositor of type 2 taking action $a_{1}$, we get when $p(1-q) d_{2} /[p(1-q)+(1-p) q]$ is more (less) than $d_{1}$, he will withdraw in period 2(1).

Then at the decision point $I_{1}$, the utilities of the depositor of type 1 taking action $a_{2}$ and $a_{1}$ are 0 and $d_{1}$ respectively, so he will take action $a_{1}$. Nevertheless, at the decision point $I_{2}$, we will discuss it in two situations. Situation 1 is that the depositor of type 2 chooses to withdraw in period 1 after receiving the signal of negative information $L$, and in the meanwhile his expected utility is $\theta p_{H} d_{2}+(1-\theta) d_{1}$. Under such situation, giving deposit contract $d_{2}$ the bank proposes, the expected utility of the depositor accepting the contract (i.e., taking action $A$ ) is:

$$
\begin{aligned}
& t d_{1}+(1-t)\left[\theta p_{H} d_{2}+(1-\theta) d_{1}\right] \\
& =t d_{1}+(1-t)\left[\frac{\theta p q d_{2}}{p q+(1-p)(1-q)}+(1-\theta) d_{1}\right]
\end{aligned}
$$


Compare equation (3) with the utility 1 of rejecting the deposit contract (i.e., taking action $R$ ), we get when $t d_{1}+(1-t)\left\{\left[\theta p q d_{2}\right] /[p q+(1-p)(1-q)]+(1-\theta) d_{1}\right\}$ is more (less) than 1 , he will accept (reject) the contract. Furthermore, situation 2 is that the depositor of type 2 chooses to withdraw in period 2 after receiving the signal of negative information $L$, and in the meanwhile his expected utility is $\theta p_{H} d_{2}+(1-\theta) p_{L} d_{2}$. Under such situation, giving deposit contract $d_{2}$ the bank proposes, the expected utility of the depositor accepting the contract (i.e., taking action $A$ ) is:

$$
\begin{aligned}
& t d_{1}+(1-t)\left[\theta p_{H} d_{2}+(1-\theta) p_{L} d_{2}\right] \\
& =t d_{1}+(1-t)\left[\frac{\theta p q d_{2}}{p q+(1-p)(1-q)}+\frac{(1-\theta) p(1-q) d_{2}}{p(1-q)+(1-p) q}\right]
\end{aligned}
$$

Compare equation (4) with the utility 1 of rejecting the deposit contract, we get when $t d_{1}+(1-t) p d_{2}\{[\theta q] /[p q+(1-p)(1-q)]+[(1-\theta)(1-q)] /[p(1-q)+(1-p) q]\}$ is more (less) than 1 , he will accept (reject) the contract.

Finally, back to the decision point $I$, the bank proposes a deposit contract $d_{2}$ to attract the depositor. The depositor of type 1 must withdraw in period 1, while after receiving negative information the depositor of type 2 also withdraws in period 1 under situation 1, yet withdrawing in period 2 under situation 2. From now on, we define the expected utility of the bank under situation 1 as $V_{B 1}$ :

$$
V_{B 1} \equiv t\left(-d_{1}\right)+(1-t)\left[\theta p\left(R-d_{2}\right)+(1-\theta)\left(-d_{1}\right)\right]
$$

And the expected utility of the bank under situation 2 is defined as $V_{B 2}$ :

$$
V_{B 2} \equiv t\left(-d_{1}\right)+(1-t)\left[\theta p\left(R-d_{2}\right)+(1-\theta) p\left(R-d_{2}\right)\right]
$$

From equation (6), we can simplify $V_{B 2}$ into $t\left(-d_{1}\right)+(1-t) p\left(R-d_{2}\right)$. Because the operation purpose of the bank is profit maximization, the following below is the subgame perfect equilibrium under two situations to separately maximize $V_{B 1}$ and $V_{B 2}$.

First, according to the assumption above, no matter under which situation, at the decision point $I_{21}$, the depositor of type 2 will withdraw in period 2 after receiving the signal of positive information $H$, that is $p q d_{2} /[p q+(1-p)(1-q)] \geq d_{1}$ transposed into:

$$
d_{2} \geq \frac{p q+(1-p)(1-q)}{p q} d_{1}
$$

If situation 1 holds, at the decision point $I_{22}$, the term of the depositor of type 2 withdrawing in period 1 after receiving the signal of negative information $L$ is $p(1-q) d_{2} /[p(1-q)+(1-p) q] \leq d_{1}$, meaning:

$$
\frac{p(1-q)+(1-p) q}{p(1-q)} d_{1} \geq d_{2}
$$

Combine equation (7) and equation (8), and we can arrange the inequality as:

$$
\frac{p(1-q)+(1-p) q}{p(1-q)} d_{1} \geq d_{2} \geq \frac{p q+(1-p)(1-q)}{p q} d_{1}
$$

It means the below conditions must be fulfilled:

$$
\frac{p(1-q)+(1-p) q}{p(1-q)} d_{1} \geq \frac{p q+(1-p)(1-q)}{p q} d_{1}
$$

We subtract the above two equations as: 


$$
\begin{gathered}
\frac{p(1-q)+(1-p) q}{p(1-q)} d_{1}-\frac{p q+(1-p)(1-q)}{p q} d_{1} \\
=\frac{p q(1-q)+(1-p) q^{2}-p q(1-q)-(1-p)(1-q)^{2}}{p q(1-q)} d_{1} \\
=\frac{(1-p)\left[q^{2}-(1-q)^{2}\right]}{p q(1-q)(1-q)} d_{1}
\end{gathered}
$$

Because of $q \in(1 / 2,1)$, the term of $(1-p)\left[q^{2}-(1-q)^{2}\right] /[p q(1-q)]>0$ is fulfilled. Next, at the decision point $I$, given deposit contract $d_{2}$, the term of the depositor accepting the contract is $t d_{1}+(1-t)\left\{\left[\theta p q d_{2}\right] /[p q+(1-p)(1-q)]+(1-\theta) d_{1}\right\} \geq 1$, meaning:

$$
d_{2} \geq \frac{\left\{1-[1-\theta(1-t)] d_{1}\right\}[p q+(1-p)(1-q)]}{(1-t) \theta p q}
$$

We make the following definition for the convenience of mathematical symbols:

$$
\begin{gathered}
\Omega_{0} \equiv \frac{\left\{1-[1-\theta(1-t)] d_{1}\right\}[p q+(1-p)(1-q)]}{(1-t) \theta p q} \\
\Omega_{1} \equiv \frac{p q+(1-p)(1-q)}{p q} d_{1} \\
\Omega_{2} \equiv \frac{p(1-q)+(1-p) q}{p(1-q)} d_{1}
\end{gathered}
$$

Equation (9) and equation (12) combined, the terms that $d_{2}$ is not less than $\Omega_{0}$ and $d_{2} \in\left[\Omega_{1}, \Omega_{2}\right]$ must be fulfilled under situation 1 . We can see the term of equation (10), $\Omega_{2}-\Omega_{1}>0$, is definitely fulfilled in the foregoing. Under $\Omega_{2}-\Omega_{1}>0$ definitely fulfilled, the terms, that $d_{2}$ must not less than $\Omega_{0}$ and $d_{2} \in\left[\Omega_{1}, \Omega_{2}\right]$, make $\Omega_{2}-\Omega_{0} \geq 0$ have to be fulfilled. In the foregoing we suppose $d_{1}>1$, so $\Omega_{1}>\Omega_{0}$, and $\Omega_{2}-\Omega_{0} \geq 0$ will be fulfilled. Because the bank will lower $d_{2}$ as far as possible to reap more benefits, we get $d_{2}=\Omega_{1}$ under situation 1 .

If situation 2 holds, at the decision point $I_{22}$, the term of the depositor of type 2 withdrawing in period 2 after receiving the signal of negative information $L$ is $p(1-q) d_{2} /[p(1-q)+(1-p) q] \geq d_{1}$, meaning:

$$
\frac{p(1-q)+(1-p) q}{p(1-q)} d_{1} \leq d_{2}
$$

Combine equation (7), equation (13) and the definition of $\Omega_{1}$ and $\Omega_{2}$, and we can get the term which $d{ }_{2}$ must not less than $\Omega_{2}$. Next, at the decision point $I$, given deposit contract $d_{2}$, the term of the depositor accepting the contract is $t d_{1}+(1-t) p d_{2}\{[\theta q] /[p q+(1-p)(1-q)]+[(1-\theta)(1-q)] /[p(1-q)+(1-p) q]\} \geq 1$, meaning:

$$
d_{2} \geq \frac{\left(1-t d_{1}\right)(2 q p-p-q)(2 q p-p-q+1)}{(1-t) p[\theta+p(2 q-1)(q+\theta-1)-q(q+2 \theta-2)-1]}
$$

We define the right side of the in inequality (14) as $\Omega_{3}$, combine the constraint on $d_{2} \geq \Omega_{2}$, and get the term which $d_{2}$ must not less than $\max \left[\Omega_{2}, \Omega_{3}\right]$. Next, we substitute $\Omega_{3}$ and $\Omega_{2}$ as $d_{2}$ into equation (4), then the results are equal to 1 and more than 1 separately, so $\Omega_{2}>\Omega_{3}$ is obtained. Because $d_{2}$ must not less than $\max \left[\Omega_{2}, \Omega_{3}\right]$ and the bank will lower $d_{2}$ as far as possible, $d_{2}=\Omega_{2}$ is obtained under situation 2. Combine the above analysis of two situations, we can get the following lemma:

【Lemma 1】 Only one deposit contract of $\Omega_{1}$ and $\Omega_{2}$ is the deposit contract equilibrium $d_{2}$. 
(1) $d_{2}=\Omega_{1}$ : The utility of the bank is $V_{B 1}$, the depositor of type 1 withdraws in period 1 , and the depositor of type 2 at $I_{21}$ withdraws in period 2 , yet at $I_{22}$ withdraws in period 1 .

(2) $d_{2}=\Omega_{2}$ : The utility of the bank is $V_{B 2}$, the depositor of type 1 withdraws in period 1 , and the depositor of type 2 at $I_{21}$ and $I_{22}$ both withdraws in period 2.

From Lemma 1 we can know the difference between the depositor decisions is just that at the decision point $I_{22}$, the depositor of type 2 will withdraw in period 1 under situation 1, while withdraw in period 2 under situation 2. Since $d_{2}$ is the protection offered to the depositor when the deposit contract expires at the end of period 2 . Different $d_{2}$ will make the depositor of type 2 have different decisions, $d_{2}$ is $\Omega_{1}$ under situation 1, yet under situation 2 is $\Omega_{2}$. Because $\Omega_{2}>\Omega_{1}$, it makes the depositor of type 2 have greater incentive to withdraw in period 2 under situation 2 rather than withdraw in period 1 under situation 1 .

Now we compare the size of $V_{B 1}$ and $V_{B 2}$ to determine the bank's optimum choice on $d_{2}$. First subtract equation (6) from equation (5), and we get: (Note 4)

$$
\frac{-d_{1}(1-t)\{\theta(1-p)+q[1-q-\theta(3-2 p-q)]\}}{q(1-q)}
$$

As $\theta$ approaches 0 , then equation (15) is less than 1 . Nevertheless, as $\theta$ approaches 1 , then equation (15) is more than 1 . Besides, we differentiate equation (15) with respect to $\theta$ and get:

$$
\frac{-d_{1}(1-t)[(1-p)-q(3-2 p-q)]}{q(1-q)}=\frac{d_{1}(1-t)[(1-p)(2 q-1)+q(1-q)]}{q(1-q)}>0
$$

Combine the interpretation of equation (15) and equation (16), and we can get the probability $\theta$ of the depositor receiving positive information is higher (lower), $V_{B 1}$ is likely to be more (less) than $V_{B 2}$, meaning the bank is likely to choose $d_{2}$ to equal to $\Omega_{1}\left(\Omega_{2}\right)$. Intuitively, although under situation 1 the bank will face the risk of the depositor of type 2 withdrawing early in period 1 after his reception of negative information, when the probability $\theta$ of the depositor receiving positive information is higher, the probability of the bank facing such a risk is lower. Moreover, under situation 1 the amount $d_{2}$ of bank giving to the depositor who withdrawals at period 2 is lower, so the bank prefers $\Omega_{1}$. On the contrary, under situation 2 the amount $d_{2}$ of bank giving to the depositor who withdrawals at period 2 is higher, but when the probability $\theta$ of the depositor receiving positive information is lower, the probability of the bank facing the risk of the depositor's withdrawal at period 1 is higher, so the bank prefers $\Omega_{2}$. Next, as $p$ approaches 0 , then we are unable to determine whether equation (15) is positive or not.(Note 5) Nevertheless, as $p$ approaches 1 , then equation (15) is less than 0 . We differentiate equation (15) with respect to $p$ and get:

$$
\frac{-d_{1} \theta(1-t)(2 q-1)}{q(1-q)}<0
$$

Combine the interpretation of equation (15) and equation (17), and we can get the probability $p$ of the bank obtaining $R$ is higher (lower), $V_{B 1}$ is likely to be less (more) than $V_{B 2}$, meaning the bank is likely to choose $d_{2}$ to equal to $\Omega_{2}\left(\Omega_{1}\right)$. Intuitively, under situation 1 the bank will face the risk of the depositor of type 2 withdrawing early in period 1 after the reception of negative information, and when the probability $p$ of the bank obtaining $R$ is lower, the probability of the bank facing such a risk is higher. Moreover, under situation 1 the amount $d_{2}$ of bank giving to the depositor who withdrawals at period 2 is lower, so the bank prefers $\Omega_{1}$. On the contrary, under situation 2 the amount $d_{2}$ of bank giving to the depositor who withdrawals at period 2 is higher, but when the probability $p$ of the bank obtaining $R$ is higher, the probability of the bank facing the risk of the depositor's withdrawal at period 1 is lower, so the bank prefers $\Omega_{2}$. On the other hand, as $q$ approaches $1 / 2$, then equation (15) is less than 0 . Nevertheless, as $q$ approaches 1 , then equation (15) is more than 0 . Next, we 
differentiate equation (15) with respect to $q$ and get:

$$
\frac{d_{1} \theta(1-t)(1-p)[1-2 q(1-q)]}{q^{2}(1-q)^{2}}>0
$$

Combine the interpretation of equation (15) and equation (18), and we can get the precision $q$ of the signal $s$ is higher (lower), $V_{B 1}$ is likely to be (more) less than $V_{B 2}$, meaning the bank is likely to choose $d_{2}$ to equal to $\Omega_{1}\left(\Omega_{2}\right)$. Intuitively, under situation 1 the bank will face the risk of the depositor of type 2 withdrawing early in period 1 after the reception of negative information, and when the precision $q$ of the signal is higher, given the reception of positive information, the probability $p_{H}$ of the bank obtaining $R$ is higher, so the probability of the bank facing such a risk is lower. Moreover, under situation 1 the amount $d_{2}$ of bank giving to the depositor who withdrawals at period 2 is lower, so the bank prefers $\Omega_{1}$. On the contrary, under situation 2 the amount $d_{2}$ of bank giving to the depositor who withdrawals at period 2 is higher, but when the precision $q$ of the signal is lower, the probability of the bank facing the risk of the depositor's withdrawal at period 1 is higher, so the bank prefers $\Omega_{2}$. Integrate the above analysis, and we can obtain the following proposition 1:

【Proposition 1】 The bank deposit contract equilibrium arose from different model parameters are as follows:

(1) When the probability $\theta$ of the depositor receiving positive information is higher (lower), $V_{B 1}$ is likely to be more (less) than $V_{B 2}$, meaning the bank is likely to choose $d_{2}$ to equal to $\Omega_{1}\left(\Omega_{2}\right)$. Moreover, as $\theta$ approaches 0 , the bank will choose $d_{2}$ to equal to $\Omega_{2}$. Nevertheless as $\theta$ approaches 1 , the bank will choose $d_{2}$ to equal to $\Omega_{1}$.

(2) When the probability $p$ of the bank obtaining $R$ is higher (lower), $V_{B 1}$ is likely to be less (more) than $V_{B 2}$, meaning the bank is likely to choose $d_{2}$ to equal to $\Omega_{2}\left(\Omega_{1}\right)$. Moreover, as $p$ approaches 1 , the bank will choose $d_{2}$ to equal to $\Omega_{2}$.

(3) When the precision $q$ of the signal $s$ is higher (lower), $V_{B 1}$ is likely to be more (less) than $V_{B 2}$, meaning the bank is likely to choose $d_{2}$ to equal to $\Omega_{1}\left(\Omega_{2}\right)$. Moreover, as $q$ approaches $1 / 2$, the bank will choose $d_{2}$ to equal to $\Omega_{2}$. Nevertheless, as $q$ approaches 1 , the bank will choose $d_{2}$ to equal to $\Omega_{1}$.

The following below we use numerical simulation calculation to show the results of Proposition 1 with the actual values of the parameters. From the foregoing we learn that equation (15) cannot be determined whether it is positive or not, and the part which the sign of equation (15) cannot be determined is:

$$
\theta(1-p)+q[1-q-\theta(3-2 p-q)]
$$

Equation (19) is set to be zero, and the solution of $\theta$ is

$$
\frac{q(1-q)}{q(1-q)+(2 q-1)(1-p)}
$$

We get equation (20) is more than 0 , then substitute $\theta=1 / 3$ into equation (19), and get $q$ is:

$$
\frac{1}{2}\left(p \pm \sqrt{p^{2}-2 p+2}\right)
$$

Next, we substitute $\theta=1 / 2$ into equation (19), and get $q$ is:

$$
\frac{1}{2}\left(2 p-1 \pm \sqrt{5-8 p+4 p^{2}}\right)
$$

Finally, we substitute $\theta=2 / 3$ into equation (19), and get $q$ is:

$$
\frac{1}{2}\left(4 p-3 \pm \sqrt{16 p^{2}-32 p+17}\right)
$$


Now we set that in Figure 2 the horizontal axis shows $p$ and the vertical axis shows $q$. The curves from upper right to lower left in Figure 2 separately represent the relationship of $q$ and $p$ when equation (21), equation (22) and equation (23) are positive. From equation (17) and equation (18) we can learn that $p$ and $q$ are respectively positive or negative associated with equation (15). It means that as $p$ is higher, $V_{B 2}$ is more likely to be greater than $V_{B 1}$, yet as $q$ is higher, $V_{B 2}$ is more likely to be less than $V_{B 1}$. As a result, the part above the curve represents the scope of $V_{B 1}>V_{B 2}$, and the part below the curve represents the scope of $V_{B 2}>V_{B 1}$.

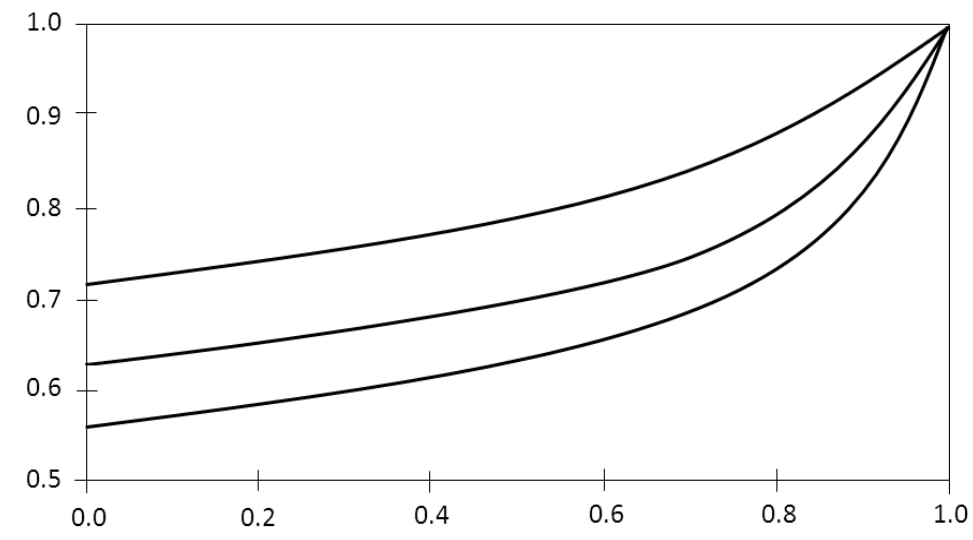

Figure 2

Besides, from Figure 2 we can learn that with the increase of $\theta$, the scope of $V_{B 1}>V_{B 2}$ is greater, meaning $V_{B 1}$ is more likely to be more than $V_{B 2}$, which represents the bank is more likely to choose $d_{2}$ under situation 1 .

\section{Bank Run}

The setting of Chen and Hasan (2008) is that as long as all the depositors withdraw at period 1, the bank run will occur, we extend their definition. From Lemma 1 we can learn that deposit contract equilibrium $d_{2}$ involve $\Omega_{1}$ under situation 1 and $\Omega_{2}$ under situation 1 . However in our model, the bank run can only happen when $d_{2}=\Omega_{1}$ which the depositor of type 1 withdraws at period 1 , and the depositor of type 2 at $I_{21}$ withdraws at period 2, while at $I_{22}$ withdraws at period 1. It makes two types of depositor may withdraw at period 1, and then leads a bank run to occur.

From the foregoing we learn that in Figure 2 the part above the curve represents the scope of $V_{B 1}>V_{B 2}$. Because under situation 1 the utility $V_{B 1}$ of the bank is higher, it makes the bank to choose deposit contract $d_{2}=\Omega_{1}$, in turn triggering the occurrence of bank runs. From Figure 1 we know that bank runs occur when negative information is revealed, the incidence of runs is $1-\theta$. On the other hand, the part below the curve represents the scope of $V_{B 2}>V_{B 1}$, and under situation 1 the utility $V_{B 2}$ of the bank is higher, so it makes the bank to choose deposit contract $d_{2}=\Omega_{2}$. Bank runs will never happen under such a situation, and the incidence of runs is 0 . This is Proposition 2:

【Proposition 2】 Only when the bank chooses $d_{2}=\Omega_{1}$ and negative information is revealed, bank runs may happen. Nevertheless, when the bank chooses $d_{2}=\Omega_{2}$, bank runs will never happen.

Meanwhile from Proposition 1 we can arrange the following Corollary 1:

【Corollary 1】 When the probability $\theta$ of the depositor receiving positive information is higher, the probability $p$ of the bank obtaining $R$ is lower, and the precision $q$ of the signal $s$ is higher, the bank is likely to choose $d_{2}$ to equal to $\Omega_{1}$, therefore bank runs are easier to occur.

Proposition 2 states that only when the bank chooses the contract $d_{2}=\Omega_{1}$ may have two types of the depositor 
both withdraws at period 1. Nevertheless, the background of economic conditions described by Corollary 1 is the condition that the bank chooses the contract $d_{2}=\Omega_{1}$. The intuitive reason of Corollary 1 already has an associated discussion before Proposition 1 is inferred. Intuitively, due to $\Omega_{2}>\Omega_{1}$, under the condition that the bank chooses the contract $d_{2}=\Omega_{1}$, because the benefits of withdrawing until the next period is relatively lower, the depositor receiving negative information tends to withdrawing early at period 1 .

Next, we discuss the similarities and differences between Chen and Hasan (2008) and our model concerned the situation of bank runs. The former emphasizes there both are an individual minimum threshold success ratio of the investment plan whether the information is revealed or not. When depositors expect the success ratio is less than the minimum threshold, the bank run phenomenon will occur. Besides, the values of two minimum thresholds are uncertain. From another point of view, the bank runs we deduce will occur when the bank proposes the deposit $d_{2}=\Omega_{1}$ and the depositor receives negative message. Known by Corollary 1 , the lower the success ratio $p$ of the investment plan, the more our model is prone to meet with a bank run. So the probability $p$ of the bank obtaining $R$ to both Chen and Hasan (2008) and our model makes an impact of the same direction on the occurrence of bank runs. It is that the lower the probability $p$ of the bank obtaining $R$, the lower the expected return got from the depositor withdrawing until the next period, so there is a strong motivation for the depositor to withdraw at period 1. In addition, the bank in our model has policy selection to the deposit contract, and in response to different economic conditions it will then select a deposit contract in advance to avoid a bank run. However, the banking industry is set to be perfectly competitive in Chen and Hasan (2008). It is the disparity between our model and Chen and Hasan (2008).

\section{Concluding Remark}

A bank runs is a phenomenon that the impacts of the panic in financial crisis or relevant negative information about the bank make depositors lose confidence in the solvency of bank, and thus large numbers of depositors seek to withdraw money from banks. Because banks will turn their deposits into other investments, they do not always retain cash meaning that the deposits which banks keep are limited. Once the bank encounters focused and intensive withdrawals, it will fall into crisis of liquidity shortage, probably leading to operational difficulties, even the risk of bankruptcy. It is seen to be a sudden and concentrated hazard. Meanwhile, the bank run is highly contagious. When a bank run occurs, if the bank does not take timely measures or obtain other assistance, it often causes a larger-scale run, thereby resulting in the collapse of the banking system, hence the government will intervene when necessary as a result.

We expand the settings of Chen and Hasan (2008), which originally assume that the bank is perfectly competitive, so the deposit contract is decided by the economic environment. We alter their model and assume that the bank owns the initiative of participating in decision making, and aims for maximizing its own benefits. They originally assume numerous depositors jointly participate in decision making, while there is only one depositor along with the bank as players in our model, and the depositor divided in two types of liquidity preference patterns will make decisions for profit maximization separately.

According to the interactive strategy game equilibrium of the bank and the depositor, the bank may propose two equilibria of the deposit contract for the depositor to accept it or not, and which deposit contract it proposes will depend on different economic conditions the bank faces. After the bank proposes the deposit contract and the depositor accepts it, the depositor in two different types of liquidity preference will decide when to withdrawal in accordance with their respective demand. We find that bank runs will occur only when the bank offer one of the contracts and the depositor receives the negative message.

Future research can be extended to the introduction of a deposit insurance system to explore whether the deposit contract the bank provides will change, or under the protection of the deposit insurance system, whether the depositor will postpone the moment of withdrawal, even whether the occurrence of bank run will be put off. On the other hand, the research can also be extended to whether the degree to how fast the depositor receives negative information will affect the occurrence of bank runs and other issues. We look forward to the follow-up extension study to better understand the actual operation of the banking system and to reduce the likelihood of bank runs. 


\section{References}

Alonso, I. (1996). On avoiding bank runs. Journal of Monetary Economics, 37, 73-87. http://dx.doi.org/10.1016/0304-3932(95)01242-7

Chari, V. V., \& R. Jaganathan. (1988). Banking Panics, Information, and Rational Expectations Equilibrium. Journal of Finance, 43, 749-761. http://dx.doi.org/10.1111/j.1540-6261.1988.tb04606.x

Chen, Y. (1999). The Role of the First Come, First Served Rule and Information Externalities. Journal of Political Economy, 107, 946-968.

Chen, Y., \& I. Hasan. (2006). The Transparency of the Banking System and the Efficiency of Information-Based Bank Runs. Journal of Financial Intermediation, 15, 307-331. http://dx.doi.org/10.1016/j.jfi.2006.01.001

Chen, Y., \& I. Hasan. (2008). Why Do Bank Run Look Like Panic? A New Explanation. Journal of Money, Credit and Banking, 40, 2-3, 535-546. http://dx.doi.org/10.1111/j.1538-4616.2008.00126.x

Cooper, R., \& T. W. Ross. (1998). Bank Runs: Liquidity Costs and Investment Distortions. Journal of Monetary Economics, 41, 27-38. http://dx.doi.org/10.1016/S0304-3932(97)00070-6

Diamond, D. W., \& P. H. Dybvig. (1983). Bank Runs, Deposit Insurance and Liquidity. Journal of Political Economy, 91, 401-419. http://dx.doi.org/10.1086/261155

Ennis, H. M., \& T. Keister. (2006). Bank Runs and Investment Decisions Revisited. Journal of Monetary Economics, 53, 217-232. http://dx.doi.org/10.1016/j.jmoneco.2004.09.006

Goldstein, I., \& A. Pauzner. (2005). Demand-Deposit Contracts and the Probability of Bank Runs. Journal of Finance, 60, 1293-1327. http://dx.doi.org/10.1111/j.1540-6261.2005.00762.x

Maeda, Y., \& Y. Sakai. (2008). Microeconomic Foundation of Lender of Last Resort from the Viewpoint of Payments. Japanese Economic Review, 59, 178-193. http://dx.doi.org/10.1111/j.1468-5876.2008.00404.x

Samartín, M. (2003). Should bank runs be prevented? Journal of Banking \& Finance, 27, 977-1000. http://dx.doi.org/10.1016/S0378-4266(02)00243-1

\section{Notes}

Note 1. The biggest difference between our paper and Chen and Hasan (2008) is that the bank in our model can actively choose the size of $d_{1}$ and $d_{2}$ to maximize its profits, and only one depositor is set to divide into two types to discuss his interactive decisions with the bank. Nevertheless, the banking system in Chen and Hasan (2008) is perfectly competitive, so the bank's decision making is relevant to market zero-profit condition, and there are large numbers of the depositors who divide into two types.

Note 2. The settings of $p_{H}$ and $p_{L}$ are similar with Chen and Hasan (2008).

Note 3. The assumption that the depositor of type 2 chooses to withdraw at period 2 after receiving positive information, is mainly to avoid the condition that two types of the depositor both withdraw at period 1 .

Note 4. The values of the equations analyzed below are all established under the assumption of $q \in(1 / 2,1)$.

Note 5. As $p$ approaches 0 , the numerator of equation (15) approaches $-d_{1}(1-t)[\theta(1-2 q)+q(1-q)(1-\theta)]$; meanwhile, as $\theta$ approaches 0 , equation (15) is less than 0 ; as $\theta$ approaches 1 , equation (15) is more than 0 . As a result, as $p$ approaches 0 , whether equation (15) is positive or not depends on other parameters. 